\title{
Determining THE STRENGTH OF COMPOSITE CYLINDRICAL BONDED JOINTS USING NUMERICAL SIMULATION WITH COHESIVE ELEMENTS
}

\author{
Frantisek Sedlacek, Tomas Kalina \& Zdenek Raab
}
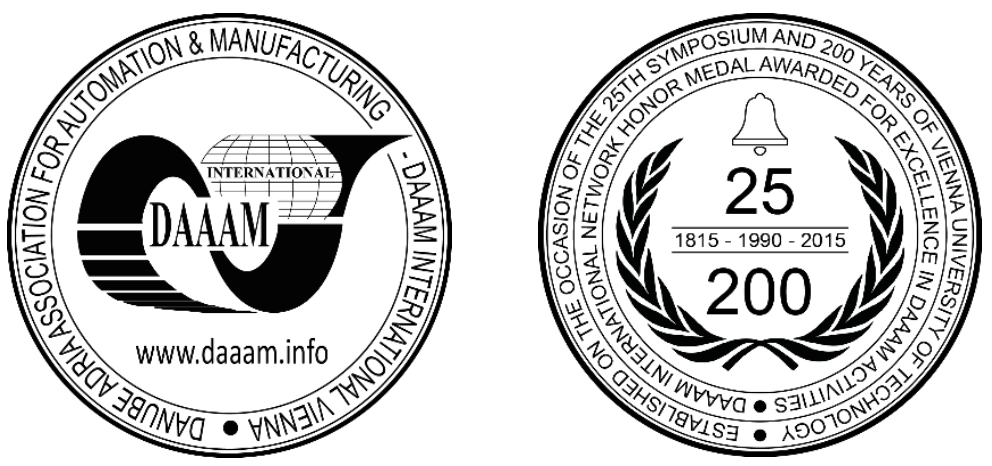

This Publication has to be referred as: Sedlacek, F[rantisek]; Kalina, T[omas] \& Raab, Z[denek] (2018). Determining the Strength of Composite Cylindrical Bonded Joints Using Numerical Simulation with Cohesive Elements, Proceedings of the 29th DAAAM International Symposium, pp.0624-0630, B. Katalinic (Ed.), Published by DAAAM International, ISBN 978-3-902734-20-4, ISSN 1726-9679, Vienna, Austria

DOI: $10.2507 / 29$ th.daaam.proceedings.090

\begin{abstract}
The adhesive joints belongs into most used connection in area of the composite components. The prediction of the strength of the bonded joints is still very problematic and many approaches can be used to dimension them. The paper deals with determining the strength of cylindrical composite adhesive joint using numerical simulation. In this case is used numerical simulation based on the finite element approach and cohesive elements were used as substitution of the adhesive. The experimental measurements were done for determination of necessary parameters of behaviour of gluing for cohesive zone model according ASTM standards. The parameters for mode I was determined by double cantilever beam test and the end notched three point bending test was carried out for finding parameters of mode II. Based on the obtained parameters, verification was performed on cylindrical samples with the accuracy up to $6 \%$.
\end{abstract}

Keywords: adhesive joint; composite material; numerical simulation; FEM; cohesive zone model

\section{Introduction}

Due to their excellent ratio of the strength, stiffness and weight, composite materials are increasingly used in many engineering areas. When the bonded joints are the most common used because the conventional fasteners (such as bolts, rivets, etc.) need to create holes in which very high stress concentrations occur (the composite materials cannot plasticize). The strength properties of bonded joints are still higher and their usage is becoming more common in very critical joints (such as wind turbines [1], aircrafts [2], automotive [3] or marine [4]).

Prediction of the strength is very problematic, a many numerical models were involved for this reason, such as: Virtual Crack Closure Technique (VCCT), Extended Finite Element Method (XFEM), Winkler-Pasternak model, Cohesive Zone Model (CZM) or its derivates such as: Discrete Cohesive Model (DCZM) or Continuous Cohesive Model (CCZM) [5], $[6]$. 
In this case, the CZM is used. This type of model is today most used. The theoretical base of CZM was developed by Barenblatt [7] and Dugdale [8] and further it was modified for engineering applications by Hillerborg [9]. The behaviour of the damage interface is in this model defined by a cohesive law that describes the relationship between the relative displacement and the interfacial stress. Many types of the cohesive laws were formulated, such as: bi-triangular, exponential, trapezoidal or polynomial. Three main modes of the crack propagation in the interface may occur: Mode Iopening mode (a tensile stress normal to the plane of the crack), Mode II - sliding mode (a shear stress is initialized parallel to the plane of the crack and perpendicular to the front of the crack) and Mode III - tearing mode (a shear stress is initialized parallel to the plane of the crack and parallel to the front of the crack).

\section{Experimental measurement of parameters of Mode I and II}

High peel and shear strength 3M $\mathrm{M}^{\mathrm{TM}}$ Scotch-Weld ${ }^{\mathrm{TM}}$ DP490 (two components epoxy adhesive) was chosen for bonding of the joints. The mechanical properties of the adhesive are given in Table 1. [10]

\begin{tabular}{|l|c|l|}
\hline$v(-)$ & 0.38 & Poisson's ratio \\
\hline$E_{0}(\mathrm{MPa})$ & 659.6 & Elastic Modulus \\
\hline$G_{v}(\mathrm{MPa})$ & 239 & Shear Modulus \\
\hline$\beta(-)$ & 0.001 & Decay Constant \\
\hline$S_{T S}(\mathrm{MPa})$ & 36.1 & Shear strength $\left(23^{\circ} \mathrm{C}\right)$ \\
\hline$S_{T P}(\mathrm{DaN} / \mathrm{cm})$ & 9.24 & Peel Strength $\left(23^{\circ} \mathrm{C}\right)$ \\
\hline
\end{tabular}

Table 1. Mechanical properties of the 3M Scotch-Weld DP490 epoxy adhesive.

The unidirectional carbon fibre laminate sheets from T300 carbon fibres and epoxy resin were used for fabrication of the test specimens with a subsequent cutting using water jet [11]. The mechanical properties of the UD CFRP sheets are given in Table 2.

\begin{tabular}{|l|c|l|}
\hline$E_{l}(\mathrm{GPa})$ & 107 & Young's Modulus $0^{\circ}$ \\
\hline$E_{2}(\mathrm{GPa})$ & 7.9 & Young's Modulus $90^{\circ}$ \\
\hline$E_{3}(\mathrm{GPa})$ & 7.9 & Young's Modulus N90 \\
\hline$G_{12}(\mathrm{GPa})$ & 4.3 & In-plane Shear Modulus in plane 12 \\
\hline$G_{23}(\mathrm{GPa})$ & 3.4 & In-plane Shear Modulus in plane 23 \\
\hline$G_{31}(\mathrm{GPa})$ & 4.3 & In-plane Shear Modulus in plane 31 \\
\hline$v_{12}(-)$ & 0.337 & Major Poisson's Ratio in plane 12 \\
\hline$v_{23}(-)$ & 0.315 & Major Poisson's Ratio in plane 23 \\
\hline$v_{31}(-)$ & 0.022 & Major Poisson's Ratio in plane 31 \\
\hline
\end{tabular}

Table 2. Mechanical properties of the UD T300 CFRP sheets.

\subsection{Experimental measurement of the mode I}

The double cantilever beam (DCB) test was used for determination of the force-displacement curves of the DCB specimens with pure mode I according ASTM standards [12]. The measuring was carried on a Zwick-Roell Z250 testing machine at ambient temperature $\left(22^{\circ} \mathrm{C}\right)$. The displacement rate of the clamps was fixed at $2 \mathrm{~mm} / \mathrm{min}$ (see Fig. 1.). The force-displacement curves of the specimens are given in Fig. 2.
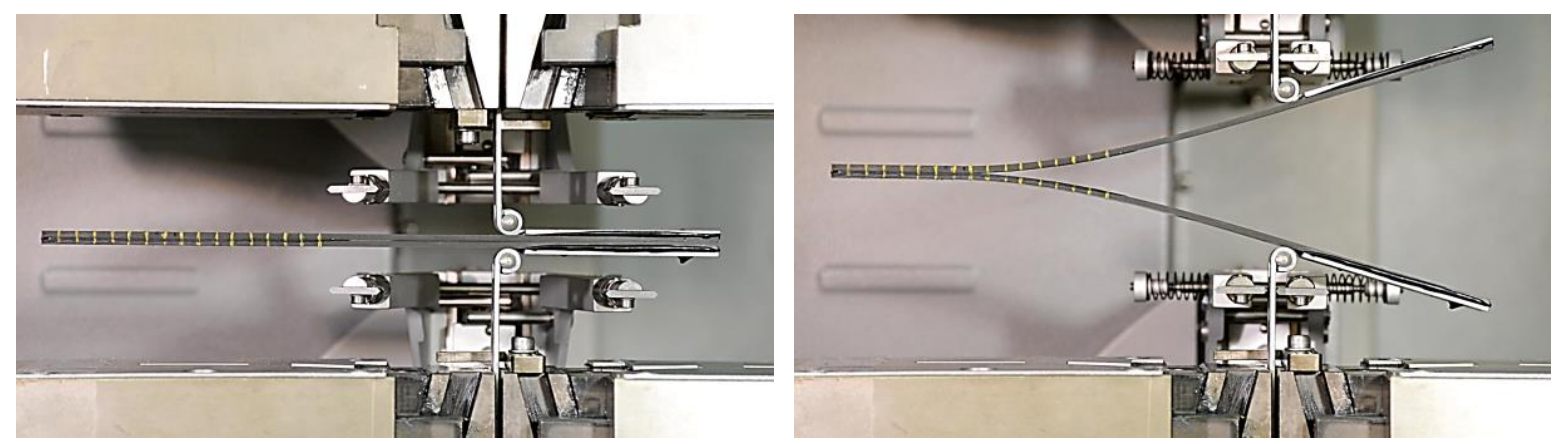

Fig. 1. Experimental test of the DCB specimens: start of the measurement (left), end of measurement (right).

The fracture energy toughness $G_{c I}^{p}\left(\mathrm{~J} / \mathrm{m}^{2}\right)$ was obtained by derivation of the experimental compliance of the specimens (see Eq. 1). 
$G_{c I}^{p}=\frac{3 F \delta}{2 b a}$

Where $\delta$ is parameter of the opening of the crack:

$\delta=\frac{2}{3} \frac{F a^{3}}{E_{x} J_{y}}+\frac{1}{4} \frac{F h^{2} a}{G_{x z} J_{y}}$

Parameter $a$ is length of the the initial crack, $b$ width of the specimen, $h$ thickness of the arm of the specimen, $E_{x}$ is effective young modulus in direction $x, G_{x z}$ is shear modulus, $J_{y}$ is quadratic moment of inertia and $F$ is force.

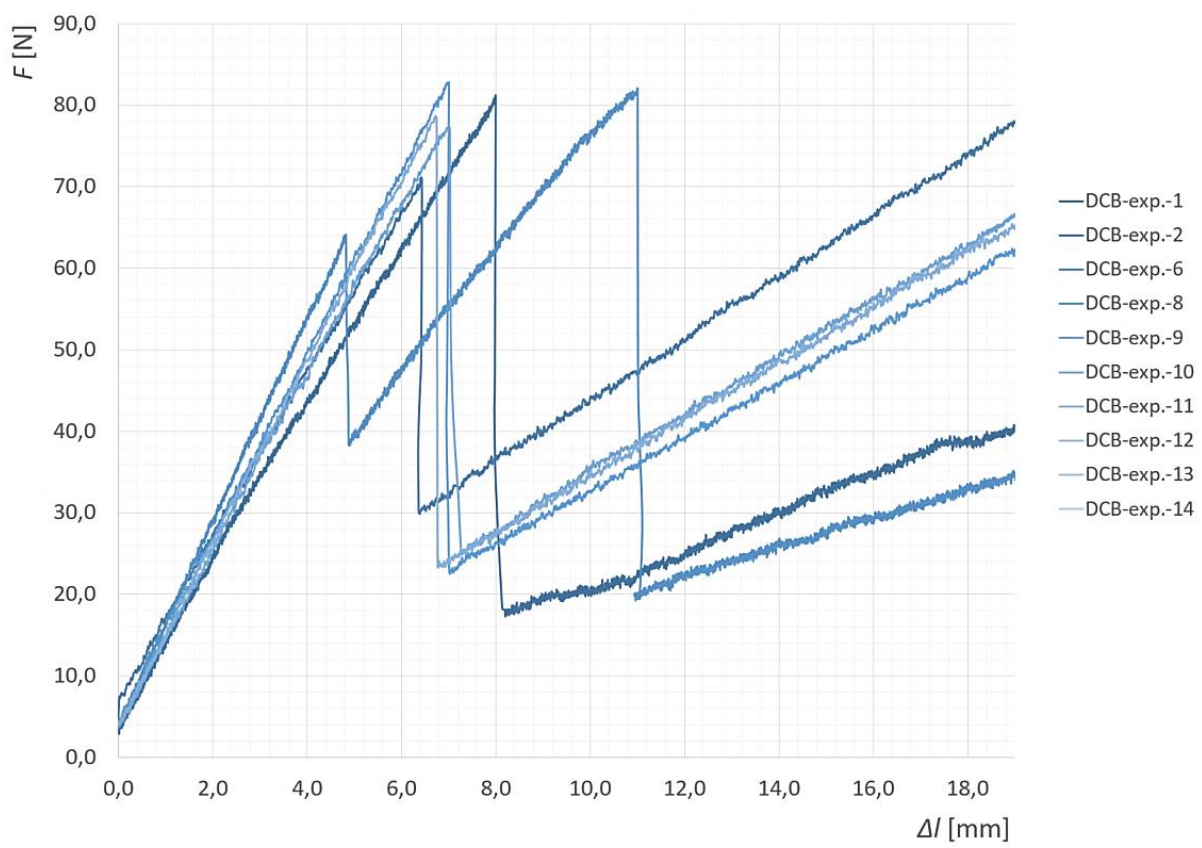

Fig. 2. Force-displacement curves of the DCB test.

\subsection{Experimental measurement of the mode II}

The end notched flexure (ENF) three point bending test was used for determination of the force-displacement curves (see Fig. 4) of the specimens with pure mode II according ASTM standards [13]. The measuring was carried on a Zwick-Roell $\mathrm{Z} 250$ testing machine at ambient temperature $\left(22^{\circ} \mathrm{C}\right)$. The displacement rate of the clamps was fixed at $2 \mathrm{~mm} / \mathrm{min}(\mathrm{see}$ Fig. 2).
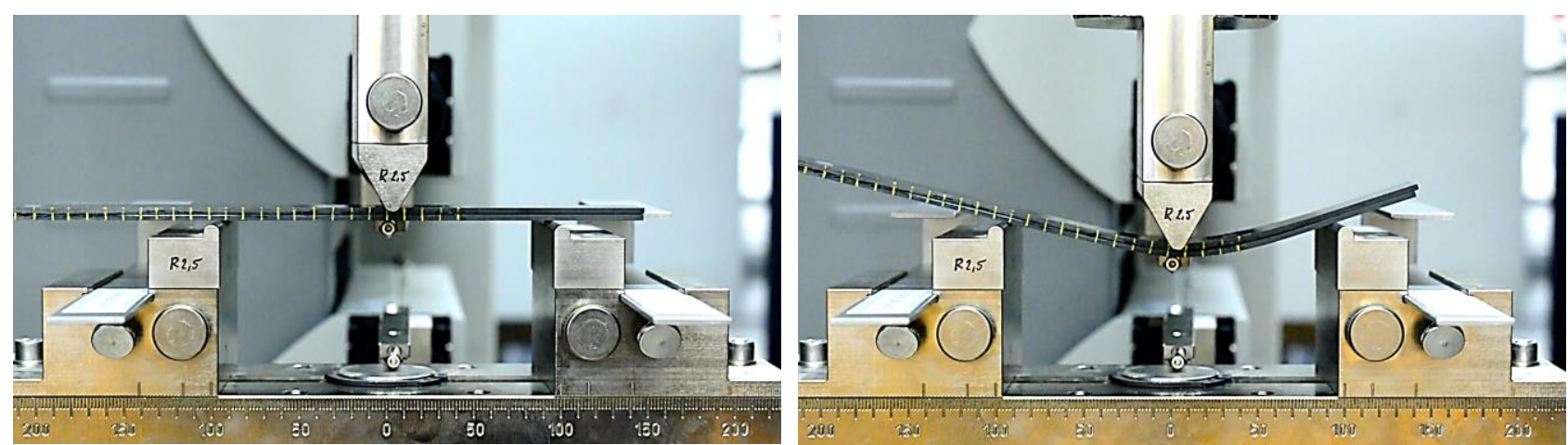

Fig. 3. Experimental test of the ENF specimens: start of the measurement (left), end of measurement (right).

Where the fracture energy toughness $G_{C I I}^{p}\left(\mathrm{~J} / \mathrm{m}^{2}\right)$ was obtained by derivation of the experimental compliance of the specimens (see Eq. 3) 


$$
G_{c I I}^{p}=\frac{9 F^{2} a^{2}}{16 b^{2} h^{3} E_{x}}=\frac{9 F a^{2} \delta}{2 b\left(3 a^{3}+2 L^{3}\right)}
$$

where:

$$
\delta=\frac{F\left(3 a^{3}+2 L^{3}\right)}{8 E_{x} b h^{3}}
$$

Parameter $a$ is length of the the initial crack, $b$ width of the specimen, $h$ thickness of the arm of the specimen, $E_{x}$ is effective young modulus in direction $x, L$ is length between force and support and $F$ is force.

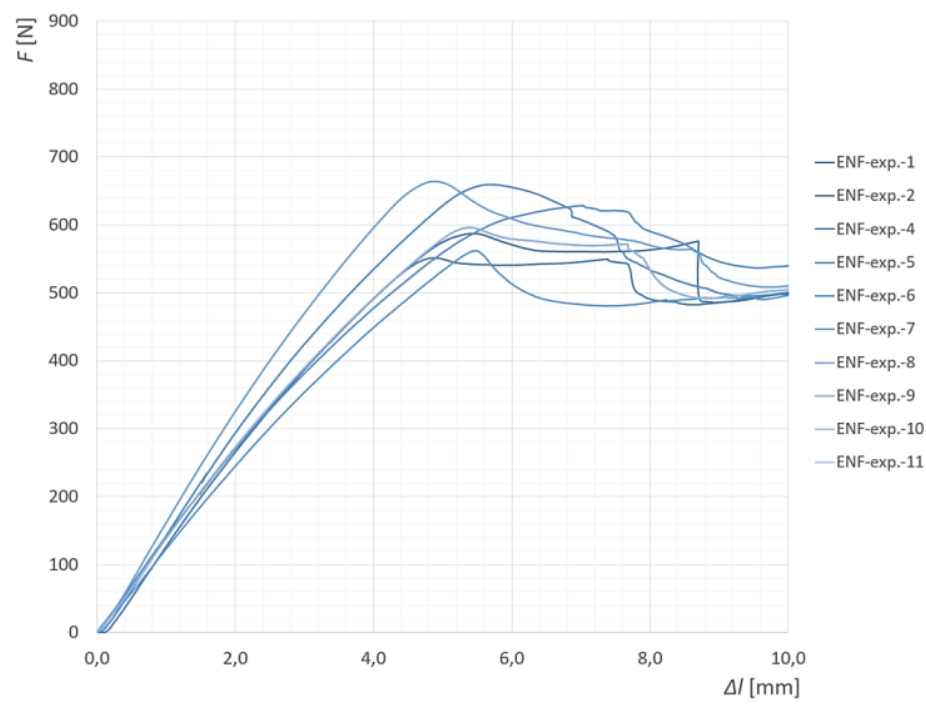

Fig. 4. Force-displacement curves of the ENF test.

\section{Determination of fracture toughness and interface stiffness with using numerical simulation}

The numerical simulation of the DCB and ENF specimens were done for determination of fracture toughness and interface stiffness of the adhesive. The values were obtained by fitting force-displacement curves from numerical simulation on curves from experimental tests. The Siemens Simcenter 3D 12 with a finite element non-linear solver NX Nastran 12 was used. The mesh of the arms of the specimens was created from parabolic hexahedral elements (CBRICK20) and the cohesive elements (T147) was used for damage interface Fig. 5.
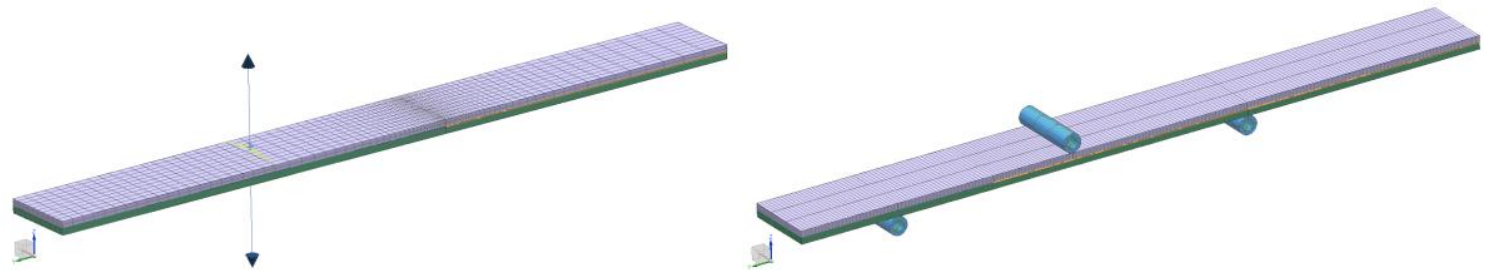

Fig. 5. FEM model with cohesive elements: DCB test (left), ENF test (right).

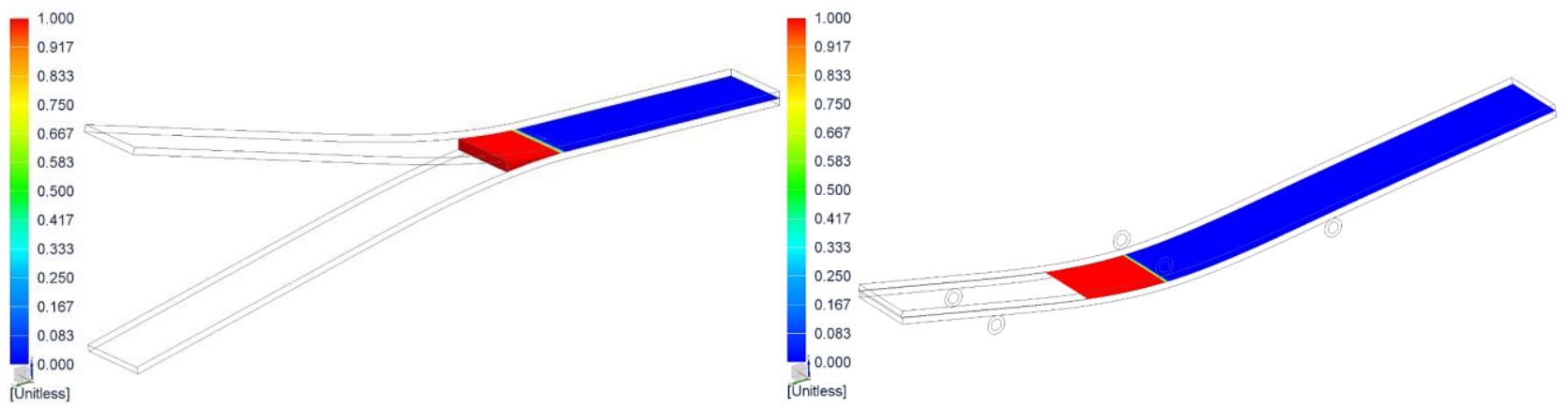

Fig. 6. Results of the damage of the interface in numerical simulation: DCB test (left), ENF test (right). 
The determined values of the transverse and shear stiffness of the interface and fracture toughness in mode I and mode II are given in Table 3 .

\begin{tabular}{|l|c|l|}
\hline$k_{03 s}\left(\mathrm{~N} / \mathrm{mm}^{3}\right)$ & 2100 & Transverse stiffness of the interface \\
\hline$k_{01}\left(\mathrm{~N} / \mathrm{mm}^{3}\right)$ & 120 & Shear stiffness of the interface \\
\hline$G_{c I}^{p}\left(\mathrm{~J} / \mathrm{m}^{2}\right)$ & 610 & Fracture Toughness - Mode I \\
\hline$G_{c L}^{p}\left(\mathrm{~J} / \mathrm{m}^{2}\right)$ & 2230 & Fracture Toughness - Mode II \\
\hline$\alpha(-)$ & 1 & Coupling coefficient \\
\hline
\end{tabular}

Table 3. Cohesive parameters of the 3M Scotch-Weld DP490 epoxy adhesive.
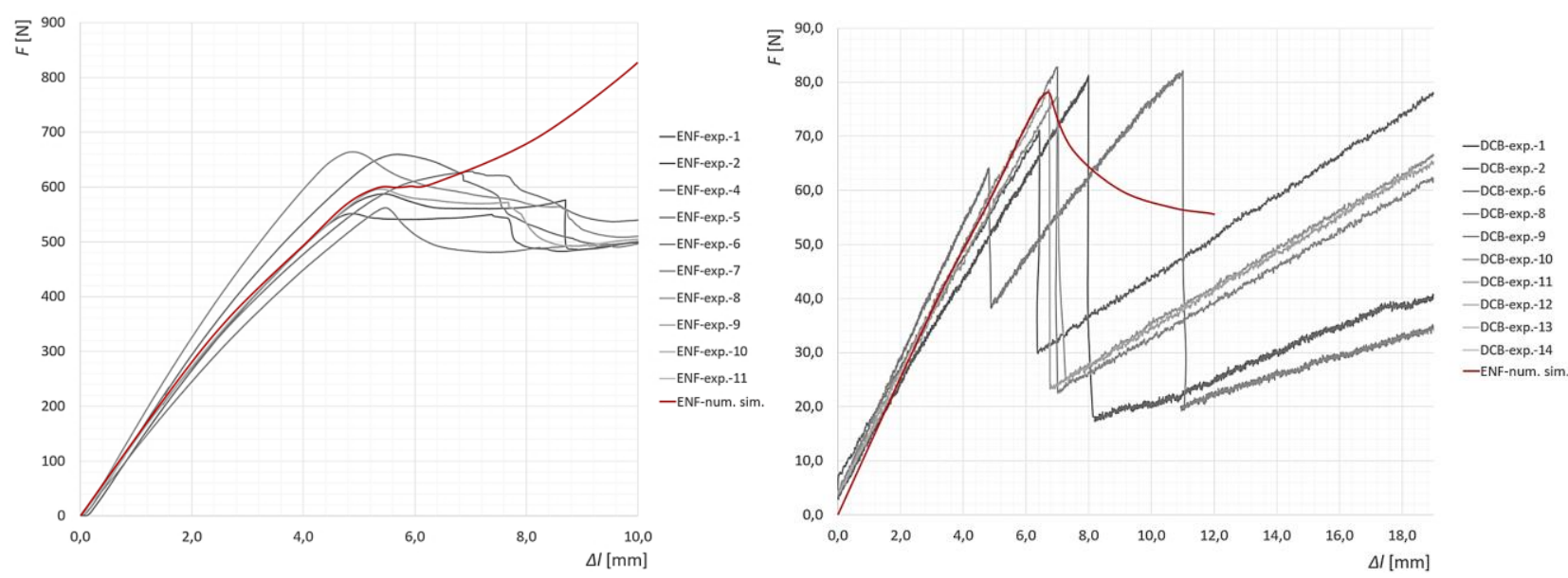

Fig. 7. Force-displacement curves of the numerical simulation: DCB test (left), ENF test (right).

\section{Experimental test of the cylindrical joint}

The specimens were fabricated from CFRP tubes and rigid steel pins. The carbon tubes were winded from Tenax STS40 F13 24k 1600tex carbon roving and Toray T700 carbon roving. The mechanical properties of the materials are given in Table 4. The measuring was done on an Inova FU O250 hydraulic testing machine at ambient temperature $\left(20{ }^{\circ} \mathrm{C}\right)$. The pins were attached in self-locking jigs and axial tensile loaded by displacement $1 \mathrm{~mm} / \mathrm{min}$. The geometrical parameters of the cylindrical specimens are given in Table 5.

\begin{tabular}{|l|c|c|l|}
\hline & Tenax STS40 F13 & Toray T700 & \\
\hline$E_{l}(\mathrm{GPa})$ & 146.9 & 145.8 & Young's Modulus $0^{\circ}$ \\
\hline$E_{2}(\mathrm{GPa})$ & 11.38 & 8.89 & Young's Modulus $90^{\circ}$ \\
\hline$E_{3}(\mathrm{GPa})$ & 11.38 & 8.89 & Young's Modulus N90 \\
\hline$G_{12}(\mathrm{GPa})$ & 5.19 & 5.6 & In-plane Shear Modulus \\
\hline$v_{12}(-)$ & 0.27 & 0.29 & Major Poisson's Ratio \\
\hline
\end{tabular}

Table 4. Mechanical properties of the STS40 and T700.
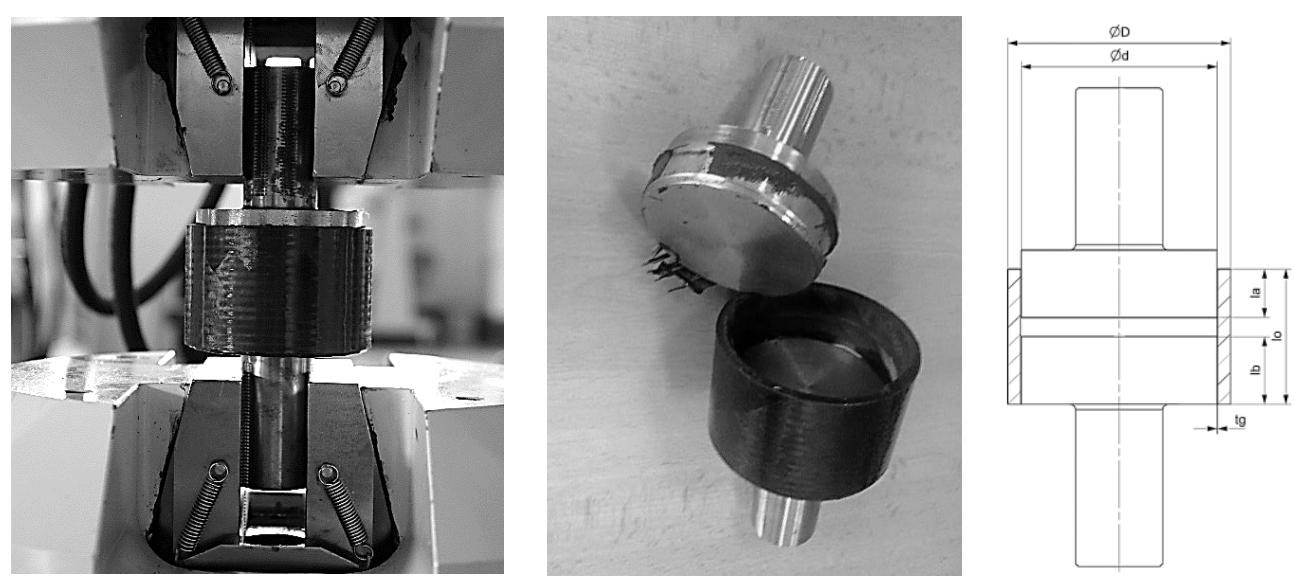

Fig. 8. Experimental tensile test of the cylindrical specimens. 


\begin{tabular}{|l|c|l|}
\hline$\emptyset d(\mathrm{~mm})$ & 72.1 & Diameter of the pin \\
\hline$\emptyset D(\mathrm{~mm})$ & 82 & Outside diameter of the tube \\
\hline$l_{a}(\mathrm{~mm})$ & 18 & Short length of the adhesive \\
\hline$l_{b}(\mathrm{~mm})$ & 25 & Long length of the adhesive \\
\hline$l_{0}(\mathrm{~mm})$ & 50 & Length of the tube \\
\hline$t_{g}(\mathrm{~mm})$ & 0.2 & Thickness of the adhesive \\
\hline
\end{tabular}

Table 5. Geometrical parameters of the cylindrical specimens.

\section{Numerical simulation of the cylindrical joint}

The 2D mapped mesh of the composite tube from CQUAD8 elements was created. The physical properties of the individual plies was defined by Ply based laminate process and the 2D mesh was subsequently filled to 3D mesh with thickness of the walls of the elements regards to thickness plies. The meshes of the steel pins were created from 3D parabolic hexahedral (CBRICK20) and tetrahedral (TET10) elements. The 3D cohesive elements with found parameters (see chapter 3) of the fracture toughness and the stiffness of the interface were used. In this case, the fitting of the fracture toughness for mode III was carried out. The highest agreement with the experiment was found for $G_{c I I I}^{p}=2460\left(\mathrm{~J} / \mathrm{m}^{2}\right)$.

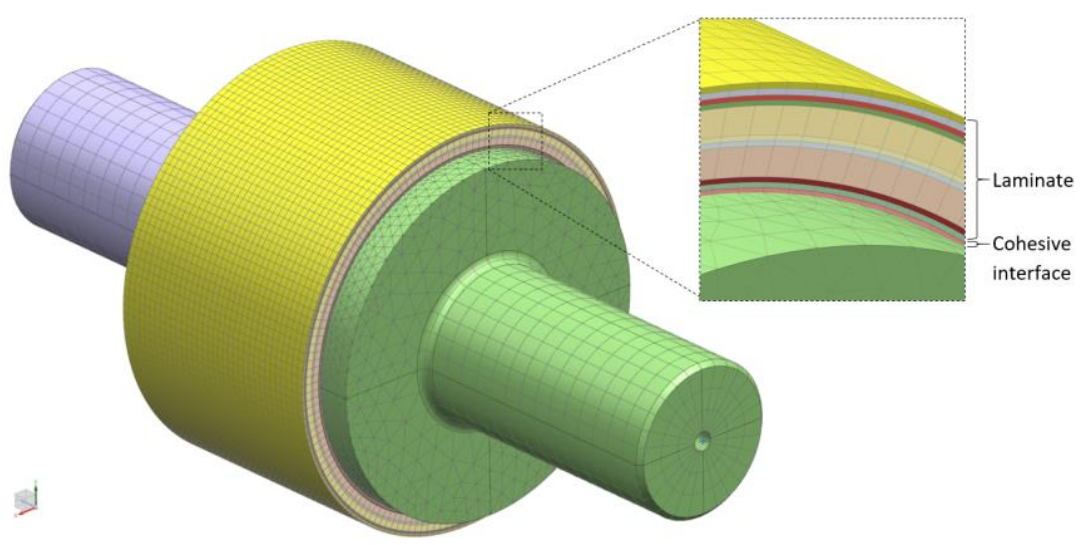

Fig. 9. FEM model of the cylindrical specimen.

\section{Results and discussion}

The agreement with experimental measurements up to $6 \%$ was found. The average maximum tensile force in the experiment reached $F_{c e \_ \text {max }}=95790 \mathrm{~N}$ and in numerical simulation $101500 \mathrm{~N}$ with the same compliance of the interface.

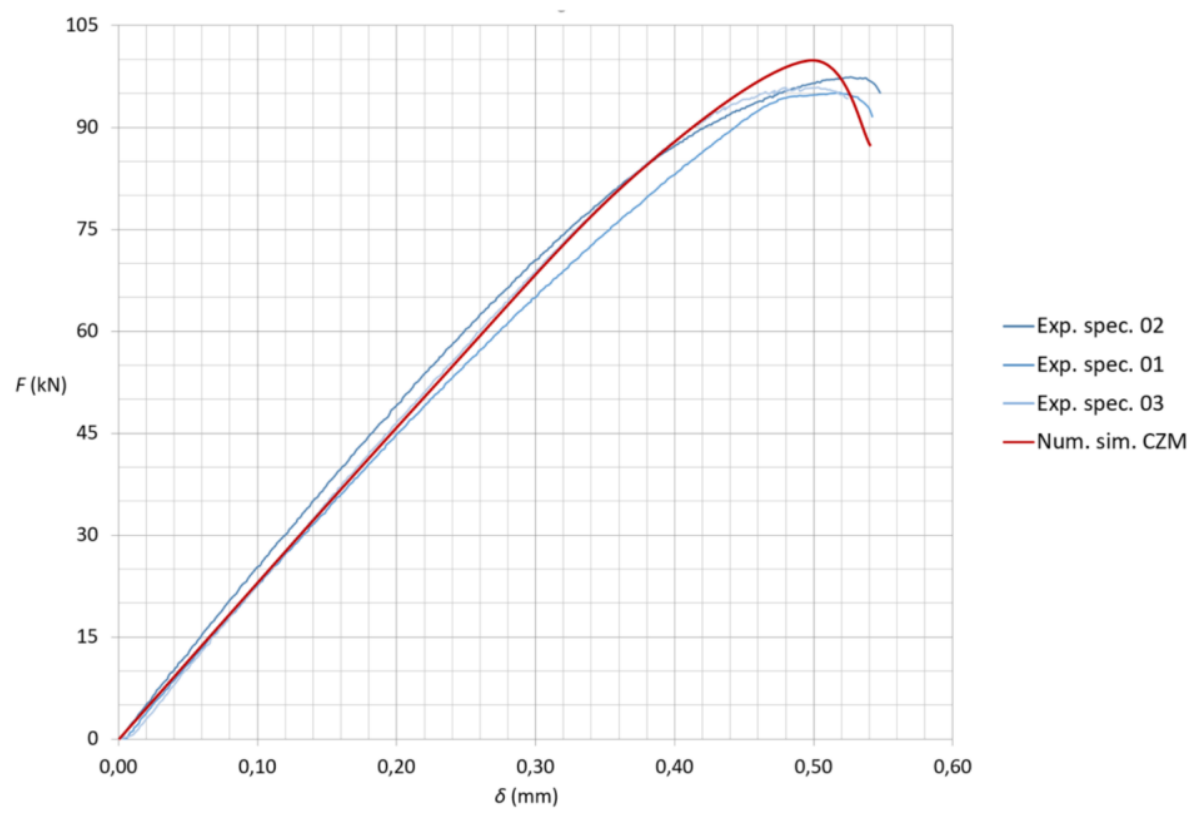

Fig. 10. Force-displacement curves of the experimental measurements and numerical simulation of the cylindrical joints. 


\section{Conclusion}

The main goal of the paper was determining of the strength of the bonded joint of the cylindrical composite tubes with steel pin using numerical simulation with cohesive zone modelling approach. The experimental measurements for mode I (DCB test) and for mode II (ENF test) was done. The fracture toughness and initial stiffness of the adhesive interface were found from measured data by using numerical simulation.

The validation of the obtained parameters was done on the cylindrical specimen of the composite tubes with steel pins. From experimental tensile test data was found last fracture toughness of the adhesive for mode III. The final results of the numerical simulation had very good agreement with experimental test up to $6 \%$. In the future, verification of bond strength will also be done for dynamically stressed bonded joints [14] and the determination of a strength of bonded joints in sandwich composite structures will be performed [15].

\section{Acknowledgments}

This contribution has been prepared under the project LO1502 'Development of the Regional Technological Institute' under the auspices of the National Sustainability Programme I of the Ministry of Education of the Czech Republic aimed at supporting research, experimental development and innovation.

\section{References}

[1] K. P. Subrahmanian and F. Dubouloz. (2009). 'Adhesives for bonding wind turbine blades', Reinf. Plast., vol. 53, no. 1, pp. 26-29.

[2] M. SatyanarayanaGupta and K. Veeranjaneyulu. (2017). 'Fabrication and Anayisis of Adhesive joints Used in Aircraft Structures', Mater. Today Proc., vol. 4, no. 8, pp. 8279-8286, Jan. 2017.

[3] R. D. Adams, J. Comyn, and W. C. Wake. (1997). Structural Adhesive Joints in Engineering, 2nd ed. Springer Netherlands.

[4] E. Jarry and R. A. Shenoi. (2006). 'Performance of butt strap joints for marine applications', Int. J. Adhes. Adhes., vol. 26, no. 3, pp. 162-176.

[5] D. Xie, M. Garg, D. Huang, and F. Abdi. (2009). 'Cohesive Zone Model for Surface Cracks Using Finite Element Analysis', in 49th AIAA/ASME/ASCE/AHS/ASC Structures, Structural Dynamics, and Materials Conference, 16th AIAA/ASME/AHS Adaptive Structures Conference,10th AIAA Non-Deterministic Approaches Conference, 9th AIAA Gossamer Spacecraft Forum, 4th AIAA Multidisciplinary Design Optimization Specialists Conference, American Institute of Aeronautics and Astronautics.

[6] L. Zhao, J. Zhi, J. Zhang, Z. Liu, and N. Hu. (2016). XFEM simulation of delamination in composite laminates', Compos. Part Appl. Sci. Manuf., vol. 80, pp. 61-71.

[7] G. I. Barenblatt. (1962). 'The Mathematical Theory of Equilibrium Cracks in Brittle Fracture', in Advances in Applied Mechanics, vol. 7, Elsevier, pp. 55-129.

[8] D. S. Dugdale. (1960). Yielding of steel sheets containing slits', J. Mech. Phys. Solids, vol. 8, no. 2, pp. $100-104$.

[9] A. Hillerborg, M. Modéer, and P.-E. Petersson. (1976). 'Analysis of crack formation and crack growth in concrete by means of fracture mechanics and finite elements', Cem. Concr. Res., vol. 6, no. 6, pp. 773-781.

[10] N. Shelton and O. Mauro. (2012). 'The Mechanical Performance of Adhesives for a Steel-Glass Composite Fa\&ccedil;ade System', Challenging Glass 3 Conf. Archit. Struct. Appl. Glass, pp. 293-306.

[11] Jenicek, S., Vratislav, K., Kalina, T., Masek, B. (2016). Use of waterjet in manufacturing test bars of high-strength steels, Annals of DAAAM and Proceedings of the International DAAAM Symposium, 27 (1), pp. 219-224.

[12] 'ASTM D5528-13'. (2013). Stand. Test Method Mode Interlaminar Fract. Toughness Unidirectional Fiber-Reinf. Polym. Matrix Compos. West Conshohocken PA.

[13] A. Standard, 'D7905/D7905M-14'. (2014). Stand. Test Method Determ. Mode II Interlaminar Fract. Toughness Unidirectional Fiber-Reinf. Polym. Matrix Compos.

[14] S. Spirk and M. Kepka. (2015). 'Tests and Simulations for Assessment of Electric Buses Passive Safety', Procedia Eng., vol. 114, pp. 338-345.

[15] Raz, K., Hora, J., Pavlata, P. (2017). Unconventional materials usage in design of vehicle bodies. Manufacturing Technology, roc. 17 , c. 5 , s. 